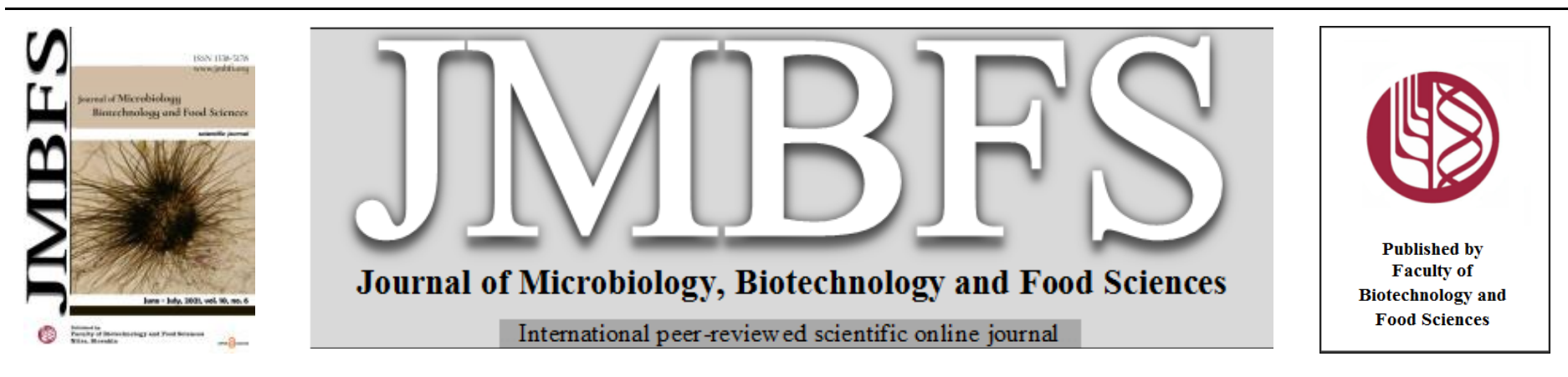

\title{
MYCOLOGICAL ANALYSIS OF DRIED FISHES COLLECTED FROM OPEN MARKETS WITH SPECIAL FOCUS ON MYCOTOXIN PRODUCTION
}

\author{
Santhanamari Thiyagarajan ${ }^{* 1,3}$ and Alruwaili Jamal ${ }^{2}$ \\ Address(es): Dr. Santhanamari Thiyagarajan, \\ ${ }^{1}$ Northern Border University, Faculty of Applied Medical Sciences, Department of Microbiology \& Immunology, Arar-91431, Kingdom of Saudi Arabia. \\ ${ }^{2}$ Northern Border University, Faculty of Applied Medical Sciences, Department of Biochemistry, Arar-91431, Kingdom of Saudi Arabia. \\ ${ }^{3}$ Asan Memorial College of Arts \& Science, P.G \& Research Department of Microbiology, Jaladampet, Chennai-600100, India.
}

*Corresponding author: Thiyagarajan.S@nbu.edu.sa

https://doi.org/10.15414/jmbfs.2236

\section{ARTICLE INFO}

Received 20. 10. 2020

Revised 3. 1. 2021

Accepted 8. 1. 2021

Published 1. 6. 2021

Regular article open $O$ access

\begin{abstract}
Dried fishes are salted and sun dried fish products consumed by large population owing to their nutrient richness, flavor and long shelf life properties. Contamination of dried fishes by mycotoxin producing fungi pose serious threat to food safety and public health. A total of 27 samples belonging to three varieties of dried fishes collected in Chennai city, India were screened for the isolation of mycotoxin producing fungal contaminants. Mycological examination of samples revealed the prevalence of six types of fungi viz., A. parasiticus (27.27\%), A. niger (22.72\%), A. fumigatus (18.18\%), Penicillium sp. (18.18\%), Cladosporium sp. (9.09\%) and Euratium sp. (4.54\%). Detection using thin layer chromatography indicated that $18.18 \%$ of isolates belonging to A. parasiticus, A. fumigatus, Penicillium sp. were positive, while A. niger, Cladosporium sp., and Euratium sp. were negative for mycotoxin production. Further to the bioassay with Artemia larvae, substantial lethality was observed with the mycotoxin of A. parasiticus (100\%), followed that of by A. fumigatus and Penicillium sp. (each 50\%). The HPLC studies indicated that the mycotoxin produced by A. parasiticus was Aflatoxin G2. Need for proper hygienic practices during processing and handling of dried fishes in order to avoid fungal contamination and likelihood mycotoxicosis in consumers has been suggested.
\end{abstract}

Keywords: Dried fish, Food intoxication, Mycotoxins, Larvicidal, Bioassay

\section{INTRODUCTION}

Fish is a nutrient rich food and its consumption as a main diet has been increasing worldwide in recent years. As its calorific content is low and hence it meets nearly $60 \%$ of total protein requirement for adults, its importance in nutrition is well recognized (Kumolu-Johnson and Ndimele, 2011; Cao and Li, 2013). Its wholesomeness can be attributed to the presence of various essential nutrients including proteins, vitamins, minerals such as calcium and phosphorus (Rafli $\boldsymbol{e}$ al., 2018). By virtue of possessing omega-3 fatty acids it offers excellent health benefits such as control of cardiovascular diseases. But, the shorter shelf life of the fish, owing to the possession of perishable food contents, constraints its availability for longer periods. Improper handling and poor storage conditions predispose high microbial contaminations and spoilage in fish and fish products (Hashem, 2011).

In order to avoid these post-harvest deteriorations and to obtain a microbiologically stable fish product, certain preservation techniques such as smoking and drying are followed. Particularly, in tropical countries fishes are subjected to salting and sun drying so as to improve their flavor and textural qualities. Dried fish is considered as a low cost fish product with a rich source of protein (42g per 100g) consumed worldwide (Rafli et al., 2018). It is salted heavily and sun dried for several days and has a cheesy odour. With its characteristic fishy flavor, it constitutes one of the traditional and delicious diet (Waagbø, 2008; Sulieman and Mustafa, 2012).

As the dried fishes have reduced water activity, microbial growth and spoilage are very much limited (Daramola et al., 2007). However, the keeping quality of dried fishes is often affected by colonization of halophilic microorganisms particularly fungal molds, which have the ability to grow well even at low water activities of around 0.85 (Rafli $\boldsymbol{e t}$ al., 2018). Contamination and spoilage of dried fishes occur rapidly during tropical and humid weather conditions (Atapattu and Samarajeewa, 1990). When fungi with a potential of toxin production contaminate the dried fish, it is considered as a serious issue of food safety. Mycotoxin, a secondary metabolite produced by molds, when associated with food borne illnesses, it can cause severe health complications (Monbaliu et al. 2010). Some of the important mycotoxins are Aflatoxins, Ochratoxin, Patulin,
Sterigmatocystin, Fumigillin, Citrinin, Roquuefortin and Gilotoxin (Speijers and Speijers, 2004). Fungi such as Aspergillus sp., Penicillium sp., Cladosporium spp., Rhizopus sp, Fusarium sp., Mucor sp., and Candida sp. are frequently implicated with the production of mycotoxins (Kholife et al., 2019).

Among the different mycotoxins, the Aflatoxins produced by some Aspergillus species are given significance from public health view point. Aflatoxin is known for its extreme cytopathic characteristics including acute liver cirrhosis and cancer up on consumption (Khlangwiset et al., 2011; Adeyeye, 2016). From the findings of animal studies these toxins have been proved to induce mutations, cause carcinogenic and teratogenic effects (Ikutegbe and Sikoki, 2014). Based on the fluorescence produced in response to UV illumination, aflatoxins have been classified into four types viz., G1, G2, B1 and B2 with the subscript numbers representing the class of compounds produced (1, major and 2 , minor) (Wild and Gong, 2009; Hassan et al., 2018). Contamination by aflatoxin is common among certain foods including peanuts, cotton seeds, corn, maize, spices and dried fish especially in conditions such as hot weather and humidity of $\geq 16 \%$ (Klich, 2006; Ikutegbe and Sikoki, 2014; Nleya et al., 2019).

Studies on mycotoxicoses drew greater attention of researchers during 1960s when the reports on first outbreak of mycotoxin associated Turkey $\mathrm{X}$ disease emerged (Do et al., 2007). Until then the medical importance of mycotoxins was not realized probably because of lack of proper detection methods. In recent years, the development of various methods of analysis helped in extensive survey and study of mycotoxins from human specimens such as urine, blood, body fluids, etc. Nevertheless, worldwide comprehensive data on mycotoxins contamination of dried fishes and their economic and health burden are scanty (Adeyeye, 2016)

The objective of present study was to investigate the occurrences of mycotoxins producing fungal contaminants in dried fishes from Chennai, a humid tropical climate associated coastal city of India. 


\section{MATERIALS AND METHODS}

\section{Collection of samples}

A total of 27 samples of dried fishes were collected from five different shops of open markets located in and around Chennai city, Tamil nadu province, India These dried fishes belonged to three varieties namely, Trichiurus savala (Ribbon fish), Scomberomorus commerson (King fish) and Stolephorus indicus (Anchovy). From each dried fish showing symptoms of spoilage and/or mold growth a sum of $50 \mathrm{~g}$ of sample was collected in sterile polythene bag and transported to the laboratory.

\section{Enumeration, Isolation and identification of fungi}

The enumeration and identification of fungi including yeasts and molds from dried fish samples was performed by the method suggested by Sulieman and Mustafa (2012) with slight modifications. One gram dried fish was crushed using mortar and pestle with the addition of required amount of sterile distilled water to obtain a homogenate of sample. The suspension was serially diluted in sterile saline from $10^{-1}$ to $10^{-6}$ per mL. From the dilutions of $10^{-3,} 10^{-4}$ and $10^{-5}$ an amount of $0.1 \mathrm{~mL}$ was inoculated onto sterile Sabourauds Dextrose Agar (SDA). The plates were incubated at $25-28^{\circ} \mathrm{C}$ for 7 to 10 days and observed for the growth of fungal colonies. Using a colony counter the enumeration of yeasts and molds was determined in units of cfu/g. The method of hyphal tip technique (Bazyani and Saadullah, 2018) was adopted for purification of fungal isolates. Macroscopic identification of mold isolates was carried out following the guidelines of Denning (2005) and Pitt and Hocking (2009) through observation of colony morphology, pigmentation and pattern of growth. Wet mount of the mold was subjected to lactophenol cotton blue staining for microscopic identification of fungi.

\section{Extraction and detection of mycotoxin}

For the extraction of mycotoxins from fungi, the cold extraction method (Hashem, 2011) was followed with slight modification. Briefly, $200 \mathrm{~mL}$ of chloroform was taken in a conical flask. SDA media with mold growth was broken into small pieces and added to chloroform. To this, $20 \mathrm{~g}$ of Cilite-545 powder was added with intermittent shaking. Then the flask was vigorously shaken at $80 \mathrm{rpm}$ for $30 \mathrm{~min}$. Subsequently, the content was filtered through Whatman No.1 filter paper into a beaker and the extract was evaporated at $50^{\circ} \mathrm{C}$ for 1 hour. This concentrated extract was mixed with $1 \mathrm{~mL}$ each of methanol and water and stored in cold room.

Detection of mycotoxins from the extract was carried out by Thin Laye Chromatography (TLC) described by Hashem (2011). Silica gel was prepare using toluene: ethyl acetate: acetic acid (80:10:10) solvent system and layered uniformly on TLC plate. Samples of extracts of different fungi were loaded onto the silica gel plate along with the positive control containing purified mycotoxins This setup was placed into TLC tank and the solvent was allowed to migrate through the gel till the end of the plate. The slide was taken out and dried for about 1 hour and then treated with aluminum chloride for $5 \mathrm{~min}$. Then the plate was exposed to long wave $(365 \mathrm{~nm}) \mathrm{UV}$ light for the detection of fluorescence from samples positive for mycotoxins. As the distance travelled by a compound is a unique identifier, based on the retention factor (Rf), presence of mycotoxins was determined in comparison with standards.

\section{Chemical analysis of mycotoxins}

High-performance liquid chromatography (HPLC) prescribed by AOAC (2005) was performed to identify and quantify the mycotoxins from the mixture of samples using Kobra cell with fluorescence detector. The sample containing the analyte (toxin) was packed in a glass or metal column along with a mobile phase of solvent. Using a high pressure pump, it was allowed to move through a stationary phase of another solvent with which the analyte interacts. Depending on the affinity, density and particle size, the analyte is retained in the stationary phase for a particular time. Standards for Aflatoxins B1, B2, G1 and G2 were run along with the samples. Subsequent to column extraction using reversed phase HPLC, determination of toxins was carried out through calculation of retention time and detection of fluorescence.

\section{In vitro assay of toxicity of Mycotoxins}

Assay of toxic effect of mycotoxin was performed using mycotoxins bioassay test described by Hartl and Humpf (2000). This bioassay determines the potency of mycotoxins in terms of their larvicidal activity. Briefly, different volumes of mycotoxin samples $(0.5,0.7$ and $1.0 \mathrm{~mL})$ were taken in separate tubes and volume of sample in each tube was made up to $2 \mathrm{~mL}$ using sterile marine water. A control tube containing $2 \mathrm{~mL}$ of marine water without toxin was also maintained. To each of these tubes an amount of 20 larvae of Brine shrimps (Artemia salina L.) was added and left at room temperature for $24-48$ hours Toxicity of mycotoxin was recorded through observing the percentage of mortality (absence of motility) of larvae.

\section{RESULTS}

\section{Isolation of fungi from dried fish}

Fungal contaminants of dried fish were isolated by standard mycological procedures. A total of 22 isolates of fungi belonging to different groups were obtained as detailed in table 1. Based on the morphological features, these isolates were identified to be of six types (Figure 1).

$\underline{\text { Table } 1 \text { Types of fungi isolated from dried-fish samples }}$

\begin{tabular}{lllcc}
\hline $\begin{array}{l}\text { S. } \\
\text { No }\end{array}$ & $\begin{array}{l}\text { Type of the } \\
\text { fungus }\end{array}$ & Morphological features & $\begin{array}{c}\text { No. of } \\
\text { isolates }\end{array}$ & Fungus identified \\
\hline 1 & TYPE-A & Yellowish colony with spherical spores & 6 & Aspergillus parasiticus \\
2 & TYPE-B & Black colonies with septate hypha and spherical spores. & 5 & Aspergillus niger \\
3 & TYPE-C & Green, powdery, septate hypha, conidiospores present. & 4 & Aspergillus fumigatus \\
4 & TYPE-D & Green colony with white margin ground, cottony, septate hypha. & 4 & Penicillium sp. \\
5 & TYPE-E & Velvety, grayish colony with septate hypha & 2 & Cladosprium sp. \\
6 & TYPE-F & Powdery, pale yellow colonies with chain like spores. & 1 & Eurotium sp. \\
\hline
\end{tabular}

The occurrence of fungal contaminants and percentage of isolation of different fungi from three dried-fish samples are presented in respectively in table 2 and Figure 2. Four out of nine samples of T. savala showed the growth of fungal contaminants. In particular, the sample 3 showed the growth of three types of fungi. While there was the growth of the fungi A. parasiticus (22.2\%) in two samples the other fungi A. niger (11.1\%), A. fumigatus (11.1\%) and Penicillium $s p$. (11.1\%) were isolated as single isolates from two samples. Growths of Cladosporium sp. and Euratium sp. were not observed in any of the samples.
Most samples (eight out of nine) of the dried-fish S. commerson were observed to be contaminated and showed the growth of all the six types of fungi. The occurrence of fungi A. parasiticus was high in this dried-fish (33.3\%). While there were moderate growths of A. parasiticus and Penicillium sp. (each 22.2\%), growths of other fungi were lower. Relatively higher contamination (six out of nine) of the dried fish $S$. indicus was observed. Contamination by all the fungi except Euratium $s p$. was recorded with this dried fish. 
Table 2 Occurrence of fungal contaminants in dried-fish samples

\begin{tabular}{|c|c|c|c|c|c|c|c|c|}
\hline \multirow{2}{*}{ Dried-Fish } & \multirow{2}{*}{ Sample no. } & \multirow{2}{*}{ Colony count $(\mathrm{cfu} / \mathrm{g})$} & \multicolumn{6}{|c|}{ Growth of different types of Fungi* } \\
\hline & & & $\mathbf{A}$ & B & $\mathbf{C}$ & D & $\mathbf{E}$ & $\mathbf{F}$ \\
\hline \multirow{9}{*}{ T. savala } & 1 & $1.9 \times 10^{3}$ & +++ & & & \multirow{9}{*}{+} & & \\
\hline & 2 & 0 & & & & & & \\
\hline & 3 & 0 & & & & & & \\
\hline & 4 & $9.2 \times 10^{4}$ & +++ & ++ & & & & \\
\hline & 5 & 0 & & & & & & \\
\hline & 6 & 0 & & & & & & \\
\hline & 7 & $2.8 \times 10^{3}$ & & & ++ & & & \\
\hline & 8 & 0 & & & & & & \\
\hline & 9 & 0 & & & & & & \\
\hline \multirow{9}{*}{ S. commerson } & 1 & 0 & & & & \multirow{7}{*}{+++} & & \multirow{9}{*}{+++} \\
\hline & 2 & $7.4 \times 10^{3}$ & ++ & +++ & & & & \\
\hline & 3 & $1.6 \times 10^{3}$ & & & & & ++ & \\
\hline & 4 & $2.9 \times 10^{3}$ & & & & & & \\
\hline & 5 & $2.2 \times 10^{3}$ & +++ & & & & & \\
\hline & 6 & $6.5 \times 10^{4}$ & & ++ & +++ & & & \\
\hline & 7 & $2.3 \times 10^{3}$ & & & & & & \\
\hline & 8 & $1.4 \times 10^{3}$ & & & & \multirow[t]{2}{*}{+} & & \\
\hline & 9 & $2.5 \times 10^{3}$ & +++ & & & & & \\
\hline \multirow{9}{*}{ S. indicus } & 1 & 0 & & & & \multirow{9}{*}{+++} & & \\
\hline & 2 & $3.6 \times 10^{4}$ & & ++ & +++ & & & \\
\hline & 3 & $2.0 \times 10^{3}$ & +++ & & & & & \\
\hline & 4 & $1.3 \times 10^{3}$ & + & & & & & \\
\hline & 5 & $2.2 \times 10^{3}$ & & & & & \multirow{5}{*}{++} & \\
\hline & 6 & 0 & & & & & & \\
\hline & 7 & $1.9 \times 10^{3}$ & & & & & & \\
\hline & 8 & $1.3 \times 10^{3}$ & & & + & & & \\
\hline & 9 & 0 & & & & & & \\
\hline
\end{tabular}

*A - Aspergillus fumigatus, B - Aspergillus niger, C - Aspergillus parasiticus, D - Cladosprium sp., E - Eurotium sp., F - Penicillium sp.
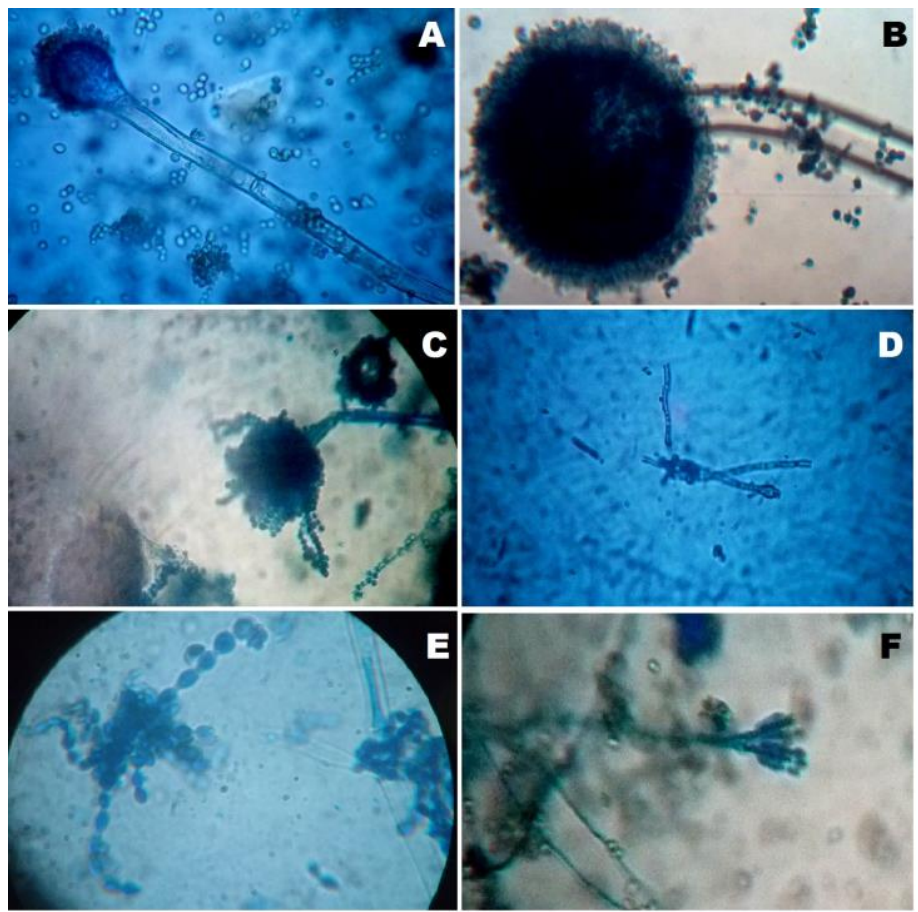

Figure 1 Fungi isolated from dried-fish samples: A - Aspergillus fumigatus, B Aspergillus niger, C - Aspergillus parasiticus, D - Cladosprium sp., E - Eurotium $s p ., \mathrm{F}$ - Penicillium $s p$.

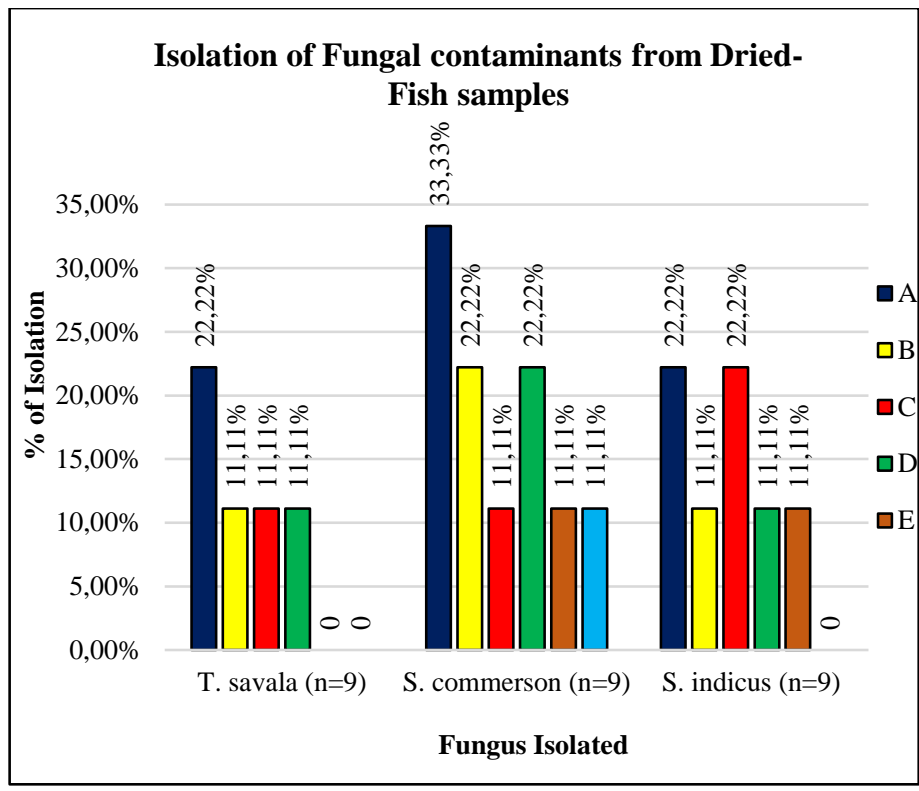

Figure 2 Isolation (\%) of fungal contaminants from Dried-fish samples

A - Aspergillus fumigatus, B - Aspergillus niger, C - Aspergillus parasiticus, D Cladosprium sp., E - Eurotium sp., F - Penicillium sp.

\section{Prevalence of fungi in dried fish samples}

Analysis of occurrences of different fungi in dried-fish samples revealed that the fungus Aspergillus parasiticus was the predominant mold (27.27\%) (Figure 3). While the other fungi were isolated at rates of $9.09-22.72 \%$, the Eurotium $s p$ was observed to be the least occurring mold $(4.54 \%)$ 


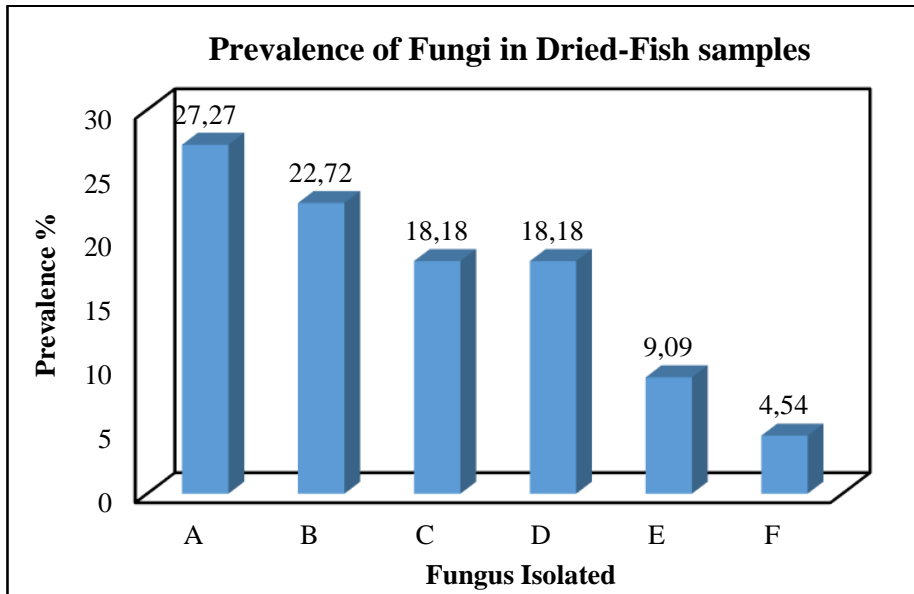

Figure 3 Prevalence of fungi in dried-fish samples

A - Aspergillus fumigatus, B - Aspergillus niger, C - Aspergillus parasiticus, D Cladosprium sp., E - Eurotium sp., F - Penicillium sp.

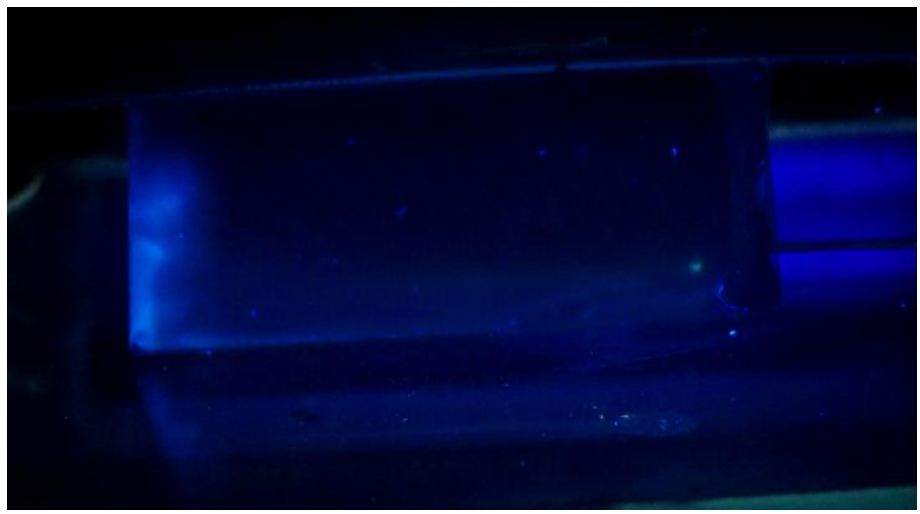

Figure 4 TLC Chromatogram showing separation of mycotoxins

\section{Screening of fungal isolates for mycotoxin production}

Further to separation of extracts of fungal isolates on TLC and exposure of isolated compounds to UV light, mycotoxins produced by the isolates were detected up on their fluorescence (Figure 4). The results of assay of mycotoxin production by different fungal isolates are given table 3 . Out of 22 isolates of fungi tested, four of them $(18.18 \%)$ were positive for mycotoxin production. The percentage of mycotoxin production among the isolates of A. parasiticus was comparatively higher than that of $A$. fumigatus and Penicillium sp.

Table 3 Results of assay of mycotoxin production by fungal isolates

\begin{tabular}{llcc}
\hline $\begin{array}{l}\text { Sl. } \\
\text { no }\end{array}$ & Fungal isolate & $\begin{array}{c}\text { No. of } \\
\text { isolates tested }\end{array}$ & $\begin{array}{c}\text { No. of } \\
\text { isolates positive }\end{array}$ \\
\hline 1 & Aspergillus parasiticus & 6 & $2(33.33 \%)$ \\
2 & Aspergillus niger & 5 & 0 \\
3 & Aspergillus fumigatus & 4 & $1(25.00 \%)$ \\
4 & Penicillium sp. & 4 & $1(25.00 \%)$ \\
5 & Cladosprium sp. & 2 & 0 \\
6 & Euratium sp. & 1 & 0 \\
\hline \multicolumn{2}{l}{ Total no. of isolates } & 22 & $4(18.18 \%)$ \\
\hline
\end{tabular}

\section{Bioassay of larvicidal activity of mycotoxins}

The lethal activity of mycotoxins was determined in terms of their ability to cause the mortality of brine shrimp larvae. While the larvicidal activity of mycotoxins of $A$. parasiticus isolates was substantial (100\%), comparatively moderate and lesser activities were exhibited by A. fumigatus (50\%) and Penicillium sp. (30\%).

\section{Chemical analysis of mycotoxins}

As the mycotoxin produced by the fungal isolate $A$. parasiticus displayed the maximum toxic potential, it was subjected to HPLC analysis for identification with reference to standard toxins. Based on the peak value and the retention time determined, this toxin was identified to be Aflotoxin G2 (Figure 5).

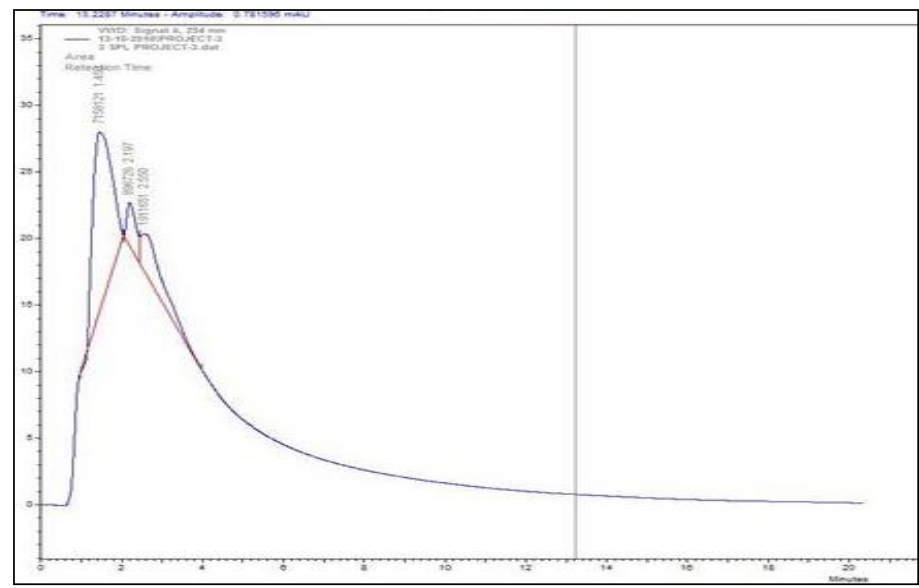

Figure 5 HPLC Chromatogram of Aflatoxin produced by Aspergillus parasiticus

\section{DISCUSSION}

By using the standard mycological procedures, a total of 22 isolates belonging to 6 groups of fungi were isolated from dried-fish samples in the present study (Tables $1 \& 2$ ). Isolation studies indicated that the samples of the dried fish $S$. commerson were more contaminated and had the growth of all the groups of fungi identified so far. Percentage of contamination in this type of dried fish was $45.5 \%$ with reference to the growth of 10 out of 22 isolates (Fig. 2). Moderate contamination $(31.8 \%)$ was recorded with the samples of dried fish $S$. indicus, which showed the growth of 7 out of 22 isolates. Contamination was lowest (22.7\%) with the dried fish T. savala, where growth of 5 out of 22 isolates of fungi was noted.

Among the different fungi isolated and identified there was a preponderance of the genus Aspergillus. These fungi constituted about $68 \%$ (15 out of 22) of the total isolates (Fig. 3). In agreement with our findings, the studies by Atapattu and Samarajeewa (1990) on fungal contaminants of different dried-fishes reported that the Aspergillus species were the predominant fungi isolated at a rate of 54\% (33 out of 61 fungal isolates). Similarly, Edema and Agbon (2010) and Ikutegbe and Sikoki (2014) independently demonstrated that the Aspergillus species were the dominant mycoflora in the samples of smoke dried fishes. Fungal species of Aspergillus genus have been reported as the most common mycoflora in tropical countries frequently implicated with the spoilage of dried foods (Pitt and Hocking, 2009).

Many studies on fungal contamination of dried fishes have reported that different species of Aspergillus such as A. niger, A. flavus, A. ochraceus, A. tamarii, etc. occur as common fungi. However, in our study the fungus $A$. parasiticus was observed to be the most common contaminant $(27.27 \%)$ followed by A. niger (22.72\%) and A. fumigatus $(18.18 \%)$. This finding is in agreement with study conducted by Youssef $\boldsymbol{e t}$ al. (2003) in Egypt where the predominant contaminant of dried fishes identified was A. parasiticus (33\%). The mold A. parasiticus is a saprophytic soil fungus often associated with spoilage of dry grains (Pitt and Hocking, 2009; Ikutegbe and Sikoki, 2014). Besides this, the fungus Penicillium species was also isolated in significant numbers $(18.18 \%)$ in our study (Fig. 3). Similar finding has been documented by Rafli et al. (2018) Essien et al. (2005) have reported that the fungal species belonging to the genus Penicillium constitute the second most contaminants of dried fishes, although they are considered as frequent spoilage organisms of temperate conditions. Swanson et al. (2011) are of the view that sun dried and salted fishes from India are often contaminated with fungal species belonging to Aspergillus and Penicillium. The dominant nature of the mold Aspergillus over Penicillium is attributed to its faster growth and production of spores of longer life which can resist sun drying and chemicals (Rafli et al., 2018).

While there was a growth of two isolates of Cladosporium sp. (9.09\%) (one each from $S$. commerson and $S$. indicus), the fungus Euratium sp. (4.54\%) was recovered as a single isolate from $S$. commerson (Table 2). Concomitant with our data few species of the genus Cladosporium have been isolated at a comparatively lower rate from dried fishes including smoked shark fishes in some studies (Atapattu and Samarajeewa, 1990; Essien et al., 2005; Erkan, 2017). Although uncommon, fungal contaminants belonging to the genus Euratium have been reported for their occurrences in salted and dried fishes of Thailand, Malaysia, Hong Kong and Pakistan (Yean et al., 2017).

The assay of mycotoxin production in our study indicated that among the fungal isolates only $18.1 \%$ (4 out of 22 ) were toxin producing, while most of them were negative $(71.9 \%)$. Lack of production of toxins by these molds could be due to hampering of their complete growth by other fast growing molds (Rafli $\boldsymbol{e t}$ al. 2018). Besides, it was noted that the fungal contaminants vary among themselves in their ability of producing the toxins (Table 3 ). While the toxin producing strains were comparatively higher among A. parasiticus $(33.3 \%)$ and fewer among A. fumigatus and Penicillium sp. (each 25.0\%), no isolate of the fungi $A$ niger, Cladosporium sp., Euratium sp. were toxin producing. In agreement with 
our findings, Youssef et al. (2003) and Ikutegbe and Sikoki (2014) have recorded the occurrence of higher frequency of mycotoxigenic strains among the isolates of $A$. paraciticus $(33.3 \%)$

The molecular determination using HPLC inferred that of mycotoxin produced by the predominant fungi A. parasiticus was Aflatoxin G2 (Fig.5). Aflatoxin is synthesized predominantly by the fungi Aspergillus flavus and Aspergillus parasiticus (Pitt and Hocking, 2009; Wild and Gong, 2009; Adeyeye, 2016). Manning (2015), who investigated the mycotoxigenic fungi from fish feeds in Egypt, reported that the isolates of the mold $A$. parasiticus were able to produce the Aflatoxins B1, B2, G1 and G2. Indeed, the toxin production by this mold was much higher than that of the co-isolate A. flavus. Extrinsic conditions favoring the mold growth and aflatoxin productions are the warm air temperature (25$35^{\circ} \mathrm{C}$ ) and a moderate relative humidity (25-35\%) (Hassan et al., 2018). Hence, it can be anticipated that Chennai with tropical weather in most part of the year meeting these conditions could support the growth of mycotoxigenic fungi in dried fishes.

Among the different species of Penicillium the only toxigenic species which commonly inhabit the dried fishes is $P$. citrinum. It produces a mycotoxin namely, citrinin which is a nephrotoxic, mutagenic, teratogenic and immunosuppressive metabolite (Yean et al., 2017). As this mold was recovered in small numbers from the dried fish samples and the toxin production was insignificant, molecular determination was not carried out in our study.

In order to confirm the lethal effect of mycotoxins produced by funga contaminants on Artemia salina larvae, in vitro bioassay was conducted. The results indicated different degrees of inhibitory effects of mycotoxins of the fungal isolates. The mycotoxin of A. paraciticus was observed to be the most potent toxin as it could kill all the larvae (100\%) under test conditions. Comparatively inferior lethality $(50 \%)$ was observed with the toxins produced by the fungi A. fumigatus and Penicillium sp. Concurrence with our study Youssef et al. (2003) have reported that while the mycotoxins of A. flavus and A. parasiticus exhibited a higher lethality $(90-100 \%)$ comparatively lower effect (78\%) was observed with that of Penicilliuim sp.

Fish and other marine products, owing to their nutrient richness and exposure to various environmental conditions during catchment, transport and in market they are prone to high contaminations. Contamination of dried fishes by fungi needs special attention as they are implicated with the production of mycotoxins on prolonged storage. The mycotoxins are given priority concern in food and health care industries in view of their potential to cause adverse health effects even a lower concentrations. Although formidable efforts are underway by FAO, UNEP and WHO for control of aflatoxins in various agriculture and animal products, least attention is paid for dried fishes. In order to ensure food safety of dried fishes, proper monitoring and quality control of their processing, transport and storage should be emphasized.

\section{CONCLUSION}

Dried fishes are consumed by large population around the world by virtue of their nutrient content, flavor and feasibility of long storage. Inadequate processing and improper handling of dried fishes pave the way for growth of contaminating microbes. Growth of fungi pose serious threat to food safety as they have the capability of producing life threatening toxins. Fungal molds commonly found in dried fishes are Aspergillus spp. followed by Penicillium sp., Cladosporium sp., Euratium sp. Favored by tropical weather conditions, these molds grow well and elaborate toxins in contaminated dried fishes. Comparatively high frequency of mycotoxin producing strains occur among the fungal species Aspergillus parasiticus. The Aflatoxin G2 produced by this predominant mold exhibit substantial lethality on in vitro bioassay against shrimp larvae. Adherence to proper hygienic practices while processing, handling and storage of dried fishes needs to be emphasized to avoid any likelihood mycotoxicosis in consumers.

Acknowledgements: The authors thank the administrative authorities of Asan Memorial College of Arts \& Science, Chennai, India for providing necessary facilities to carry out the experimental part of this study.

\section{REFERENCES}

Adeyeye, S. A. (2016). Fungal mycotoxins in foods: A review. Cogent Food \& Agriculture, 2(1), 1213127. http://dx.doi.org/10.1080/23311932.2016.1213127 Association of Official Analytical Chemists (AOAC) (2005). Van Nostrand's Encyclopedia of Chemistry. http://dx.doi.org/10.1002/0471740039.vec0284

Atapattu, R., \& Samarajeewa, U. (1990). Fungi associated with dried fish in Sri Lanka. Mycopathologia, 111(1), 55-59. http://dx.doi.org/10.1007/bf02277304

Bazyani, L. F., \& Saadullah, A. A. (2018). Mycoflora and incidence of aflatoxin in wheat seeds from Duhok province, Kurdistan region of Iraq. Science Journal of University of Zakho, 6(3), http://dx.doi.org/10.25271/sjuoz.2018.6.3.505

Cao, Y., \& Li, D. (2013). Impact of increased demand for animal protein products in Asian countries: Implications on global food security. Animal frontiers, 3(3), 48-55. http://dx.doi.org/10.2527/af.2013-0024
Daramola, J. A., Fasakin, E. A., \& Adeparusi, E. O. (2007). Changes in physicochemical and sensory characteristics of smoke-dried fish species stored at ambient temperature. African Journal of Food, Agriculture, Nutrition and Development, 7(6). http://dx.doi.org/10.18697/ajfand.17.1980

Denning, D. W. (2005). Book Review MA Klich, Identification of Common Aspergillus Species, ASM Press, Washington, DC, 2002, 116 pp. Mycopathologia, 159(1), 89. http://dx.doi.org/10.1007/s11046-005-5065-0

Do, J. H., \& Choi, D. K. (2007). Aflatoxins: detection, toxicity, and biosynthesis Biotechnology and Bioprocess Engineering, 12(6), 585-593. http://dx.doi.org/10.1007/bf02931073

Edema, M. O., \& Agbon, A. O. (2010). Significance of fungi associated with smoke-cured Ethmalosa fimbriata and Clarias gariepinus. Journal of food processing and preservation, 34, 355-363. http://dx.doi.org/10.1111/j.17454549.2009.00426.x

Erkan, N. (2017). The effect of active and vacuum packaging on the quality of turkish traditional salted dried fish "çiroz". Food and Health, 3(1), 29-35. http://dx.doi.org/10.3153/jfhs17004

Essien, J. P., Ekpo, M. A., \& Brooks, A. A. (2005). Mycotoxigenic and proteolytic potential of moulds associated with smoked shark fish (Chlamydoselachus anguincus). Journal of Applied Sciences and Environmental Management, 9(3), 53-57. http://dx.doi.org/10.4314/jasem.v9i3.17352

Hartl, M., \& Humpf, H. U. (2000). Toxicity assessment of fumonisins using the brine shrimp (Artemia salina) bioassay. Food and Chemical Toxicology, 38(12), 1097-1102. http://dx.doi.org/10.1016/s0278-6915(00)00112-5

Hashem, M. (2011). Isolation of mycotoxin-producing fungi from fishes growing in aquacultures. Research Journal of Microbiology, 6(12), 862 http://dx.doi.org/10.3923/jm.2011.862.872

Hassan, F. F., Hussein, H. Z., \& Hawar, S. N. (2018). Detection and Detoxification of Aflatoxin B1 from Fish Feedstuff Using Microwave and Ozone Gas. Ibn AL-Haitham Journal For Pure and Applied Science, 31(1), 28-36. http://dx.doi.org/10.30526/31.1.1847

Ikutegbe, V., \& Sikoki, F. (2014). Microbiological and biochemical spoilage of smoke-dried fishes sold in West African open markets. Food Chemistry, 161, 332-336. http://dx.doi.org/10.1016/j.foodchem.2014.04.032

Khlangwiset, P., Shephard, G. S., \& Wu, F. (2011). Aflatoxins and growth impairment: a review. Critical reviews in toxicology, 41(9), 740-755. http://dx.doi.org/10.3109/10408444.2011.575766

Kholife, M. M., Moawad, A. A., Diab, A. M., \& Abeer, E. K. (2019) Mycological examination of fish feed stuff with special reference to mycotoxin production. Slovenian Veterinary Research, 56. http://dx.doi.org/10.26873/svr769-2019

Klich, M. A. (2006). Book Review: DE Diaz (ed), The Mycotoxin Blue Book, Nottingham University Press, Thrumpton, Nottingham, UK. 2005, 349 pp. \$99.99. Mycopathologia, 161(5), 343. http://dx.doi.org/10.1007/s11046-006 0007-z

Kumolu-Johnson, C. A., \& Ndimele, P. E. (2011). A review on post-harves losses in Artisanal fisheries of some African countries. Journal of fisheries and Aquatic Science, 6(4), 365. http://dx.doi.org/10.3923/jfas.2011.365.378

Manning, B. B. (2015). Mycotoxin Contamination of Fish Feeds. In Dietary Nutrients, Additives, and Fish Health (pp. 237-248). Hoboken, NJ, USA: John Wiley \& Sons, Inc. http://dx.doi.org/10.1002/9781119005568.ch11

Monbaliu, S., Van Poucke, C., Detavernier, C. L., Dumoulin, F., Van De Velde, M., Schoeters, E., ... \& De Saeger, S. (2010). Occurrence of mycotoxins in feed as analyzed by a multi-mycotoxin LC-MS/MS method. Journal of Agricultural and Food chemistry, 58(1), 66-71. http://dx.doi.org/10.1021/jf903859z

Nleya, N., Ngoma, L., \& Mwanza, M. (2019). Aflatoxin Occurrence in Dairy Feeds: A Case of Bulawayo, Zimbabwe. In Aflatoxin B1 Occurrence, Detection and Toxicological Effects. IntechOpen. http://dx.doi.org/10.5772/intechopen.88582

Pitt, J. I., \& Hocking, A. D. (2009). Fungi and food spoilage (Vol. 519). New York: Springer. http://dx.doi.org/10.1007/978-0-387-92207-2

Rafli, Z. K., Damara, D. P., Andika, S., Widiastuti, S., Anggrahini, S., Agustinus, P. R., \& Endang, S. R. (2018). Mold contamination and aflatoxin B1 levels in salted fish commodities from traditional market in Yogyakarta and Surabaya, Indonesia. Malaysian Journal of Microbiology, 14(2), 691-698. http://dx.doi.org/10.21161/mjm.116117

Speijers, G. J. A., \& Speijers, M. H. M. (2004). Combined toxic effects of mycotoxins. Toxicology letters, 153(1), 91-98. http://dx.doi.org/10.1016/j.toxlet.2004.04.046

Sulieman, A. E., \& Mustafa, W. A. (2012). Quality characteristics of dried fish obtained from Eldeim Area, Central Sudan. International J Food Sci Nutr Engineering, 2(1), 1-6. http://dx.doi.org/10.5923/j.food.20120201.01

Swanson, K. M. (2011). Fish and Seafood Products. In Microorganisms in Foods 8 (pp. 107-133). Springer, Boston, MA. http://dx.doi.org/10.1007/978-1-44199374-8_10

Waagbø, R. (2008). Reducing production-related diseases in farmed fish. In Improving farmed fish quality and safety (pp. 363-398). Woodhead Publishing. http://dx.doi.org/10.1533/9781845694920.2.363 
Wild, C. P., \& Gong, Y. Y. (2010). Mycotoxins and human disease: a largely ignored global health issue. Carcinogenesis, 31(1), 71-82.

http://dx.doi.org/10.1093/carcin/bgp264

Yean, Y. S., Pruthiarenun, R., Doe, P., Motohiro, T., \& Gopakumar, K. (2017).

Dried and Smoked Fish Products. In Fish Drying \& Smoking (pp. 47-87). Taylor

\& Francis, NY. http://dx.doi.org/10.1201/9780203756003-3

Youssef, M. S., Abo-Dahab, N. F., \& Farghaly, R. M. (2003). Studies on

Mycological Status of Salted Fish "Moloha" in Upper Egypt. Mycobiology,

31(3), 166-172. http://dx.doi.org/10.4489/myco.2003.31.3.166 